\title{
AN APPROACH TOWARDS THE CONSTRUCTION OF A DIGITAL ATLAS FOR THE DOCUMENTATION OF CLOISTER AND COURTYARDS IN ASCOLI PICENO
}

\author{
Elena Ippoliti ${ }^{\text {a }}$ Daniele Rossi ${ }^{\text {b }}$, Alessandra Meschini ${ }^{\text {b }}$, Annika Moscati ${ }^{\text {a }}$ \\ ${ }^{a}$ Dipartimento di Storia, Disegno e Restauro dell'Architettura, Sapienza, Università di Roma \\ ${ }^{\mathrm{b}}$ Scuola di Architettura e Design di Ascoli Piceno, Università di Camerino
}

KEY WORDS: Digital Atlas, Semantic organization, Image Based Modeling, Map editing, Cultural Heritage

\begin{abstract}
:
The following article aims to present the results of a research experience that defines a geographic information system oriented at the architecture of closed areas of cloisters and courtyards of the historic center of Ascoli Piceno. This experimentation is part of the scenery of documentation's activities for the management and the enhancement of urban environmental improvements through the use of integrated technologies closed and open source. Therefore the main object of the analysis was the architectural one, in its different, articulated and individual features, but always considered in relation to the same geographical location, in this case the urban space, consequently focused not only on the object itself, but also on the relationship between this and any other similar ones. In this sense, the tested geographic information system is intentionally hybrid. We wanted to check the possibility of binding different shape and nature data to the "map" by structuring in a well organized manner different information - drawings, videos, photos, 3D, etc.. - in order to realize a GIS that would allow to analyze the architecture of cloisters and courtyards both in its relations to the urban context and in its specific spatial qualities.
\end{abstract}

\section{CULTURAL HERITAGE AND GEOGRAPHIC INFORMATION}

\subsection{Introduction}

The experience of research that the article aims to explain derives from the conviction that to handle and increase the value of the cultural heritage is not only necessary to know it in every single form, but the proper communication towards the direction of the widest possible dissemination.

The first action in the direction of knowledge and documentation of cultural heritage is achieved through the inventory and cataloguing activities. This is essentially based on two principles: to gather information about a single object and to contextualize these data by reference to the single object to its geographical area. The most general goal is therefore to build information not only on the single object, but on the entire system, highlighting the good relations that the individual has with the context to which he belongs.

The individual artefacts are elements of a territorial fabric to which they are significantly connected. On one hand, the geographic distribution and relative territorial relations among artefacts allow us to build upon our knowledge of the individual artefact, while on the other, the sum of territorial relations are a cultural heritage themselves, and not only a simply support for understanding. The appreciation in value which geographical information transmits to the object under study is therefore clear. Although now technically routine, the digital integration of geographical information (or experiments of GIS applications) allows the carrying out of spatial analysis as well as the spatial representation of non-spatial information, digitally integrating different types of data and becoming the principal portal for data sharing.

The experiments in the field of GIS about architectural and urban heritage are rare and unsystematic, largely due to the complexity of the issue to be investigated according to different points of view. This finding has motivated even more the purpose of the experience presented here, carried out on the courtyards and cloisters as architectural elements particularly common and distinctive in the urban space of Ascoli Piceno's center.

In general, we could say that GIS applications would be particularly interesting if carried on historic urban space because it is a complex artefact, result of successive transformations and layers, where the relationship between the single building and other buildings, between the individual building and the whole city, between downtown and the territory, etc. are large. For these specific features the urban space seems particularly appropriate for testing of GIS applications, where it is possible to interact skills and knowledge of different kinds.

\subsection{Between urban space and architectural space: the map}

In a geographic information system all the information are linked and interpreted through a geographical object which has a defined shape and appearance and an accurate georeferencing. In this way, the geographic component becomes the connection for different types of data and above all evolves from the point of view of access and information sharing.

Attention is thus given not only to the object itself, but also to its relationships with other similar and/or coeval artefacts and the entire context. The actions for the preservation of property will expand and turn into development through the deepening of knowledge, critical and scientific, and its share of this by means of an immediate and comprehensive communication, effectively achieved today through the use of information technology.

These models allow a searching method based on perceptive criteria and privilege observations and researches starting from 
the interaction of the consumer with the three-dimensional space of cultural heritage. In addition, the experiment was carried out with the intention of identifying a possible "operative practice" feasible in "limited" operational conditions: ie with no high performance equipment (personal computers and photographic equipment in common use), open source and/or low cost software and about items described as "critical", but of course with attention on the quality of processed data. These "limit" conditions have been imposed with the aim to identify a possible procedure easily accessible and practical, thus allowing large-scale applications without significant investment of financial commitment. So an experience that allows it to be "realistic" effective actions for the protection, management and promotion of cultural heritage through the identification of "expeditious and inexpensive mode" is useful for the construction of both knowledge and the widest dissemination and sharing of this.

\subsection{The choice of the case study: the closed areas of Ascoli Piceno}

The case study is the city of Ascoli Piceno, where it is particularly evident that the Forma Urbis was built around the shape and the character of the site. The main urban signs are the orthogonal matrix of Roman origin and the medieval polycentric geometry.

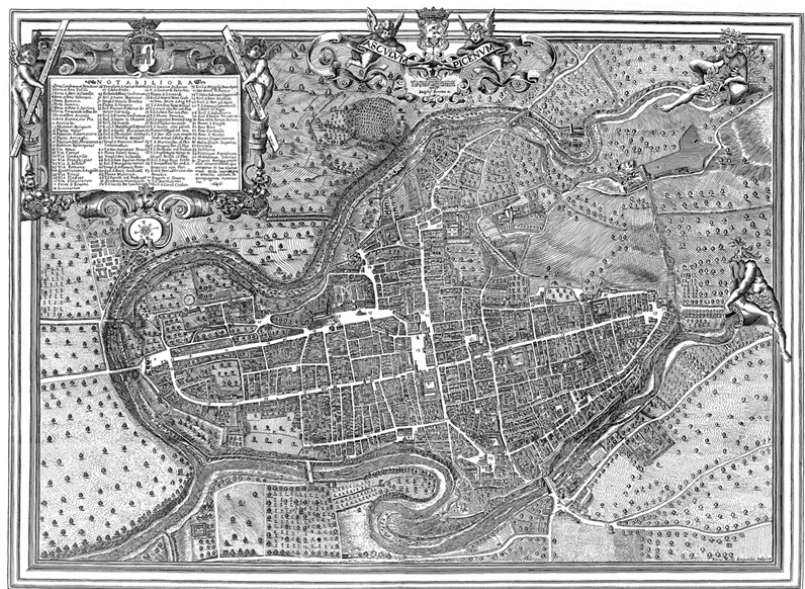

Figure 1. Plant of Ascoli Piceno, Emidio Ferretti, 1646

From this finding, the study was aimed at understanding how the urban form of the city has been able to regenerate itself, adapting to different needs, without ever erase the traces of past events, history, thus demonstrating a particular ability to adapt to different and new needs. It has therefore sought to identify a potential key to better understand the meaning of the principal descriptions that have been made of the urban landscape of the city, which highlight the "synthesis" among opposite qualities: uniformity and diversity, continuity and permeability, rational geometry and geomorphological articulation. This key has been traced by us in the role that the empty - the open space - rather than full, played in the pattern of its urban form.

First the role of the empty is read into the system of urban green spaces, but also the void resolves the relationships between public and private space. If the city seems at first sight compact and impenetrable, a more careful reading shows that it is possible to cross it in all directions. The open space, the collective space, does not end in the road's plan, but comes in churches, cloisters, courtyards, gardens, in the entry of public buildings and those in private buildings, redesigning the city. Certainly the porch is the urban-architectural material that allowed the city of Ascoli Piceno to adapt its urban structure. A spatial-volumetric structure, repeatable and serial can be adapted to satisfy the diverse needs of urban renewal.

In the Middle Ages, for example, a fabric disposed obliquely respects the previous implant overlaps itself at the strictly orthogonal of roman castrum, whose nodes are identified in new emergencies - convents and monasteries, located on the edge of the new roman city. The porch allows to manipulate the shape of the city to build a new space organization in multicenter and multifocal nature. In fact, the main monastic complex, which regulates the urban fabric of the medieval city, has its nucleus in the cloisters bordered by arcades and loggias. The porch can assume gigantic dimensions (as in the old cloister of the St. Angelo Magno, powerful monastery of Benedictine monks), or present round arches on octagonal pillars (as in the cloister of the former Convento dell'Annunziata), or even have squat columns supporting lancet arches (as in the former cloister attached to the ex Collegiata di San Tommaso Church). But again, the portico surrounds and defines the cloisters of many other monasteries of Ascoli, including the principals of Sant'Andrea, Sant'Agostino, San Pietro Martire, San Francesco, Sant'Antonio Abate and so on.

Even in the Renaissance the material used to reshape the city is the porch, that allows to adapt the buildings and monuments to the new rules of decorum cities without introducing profound structural distortions at the city.

The most striking example is Piazza del Popolo, physical and symbolic heart of the city's history. In the 15th century, the architectural image of the square was totally mixed, with the side of the church of San Francesco, the facade of Palazzo dei Capitani del Popolo, the private construction constituted by the succession of single-family homes. Even the urban space was unbalanced: on one hand the great mass of public buildings and on the other the small medieval buildings.

The porch allows you to create a urban scale architectural project. The medieval building has been preserved through the juxtaposition of new facades, but to preserve the pre-existing one, the various field has a constant variation of intercolumni and therefore of the arches, which are round, lancet or segmental.

The redefining of the city's image during the Renaissance is not just about major emergencies, but especially turned to the remodelling of the minor fabric building. It was necessary to give a residence at the family adapted to its new role: ie by adopting the type of building that is now diffused throughout central Italy. It was decided not to build new ones, but to realize them through the reshuffle and the merging of medieval serial buildings. The process of recasting was therefore never complete, but was only made the restoration of the facades according to a classic layout and especially the redefinition of the distribution system.

The porch is an architectural element that resolves the new functional and planimetric needs. This solves the problem of distribution through the introduction of a courtyard, rarely complete, that is enclosed on all four sides, more often two or three sides, surmounted by one or two orders of arcades, which provides access, through the body scale, at the different floors of the building. The courtyard can then also incorporate the small medieval streets (Rue). Through the various compositions, the volumetric-spatial structure of the porch adapts itself once again to address the different needs of urban renewal without erasing the traces of urban history of the city. 


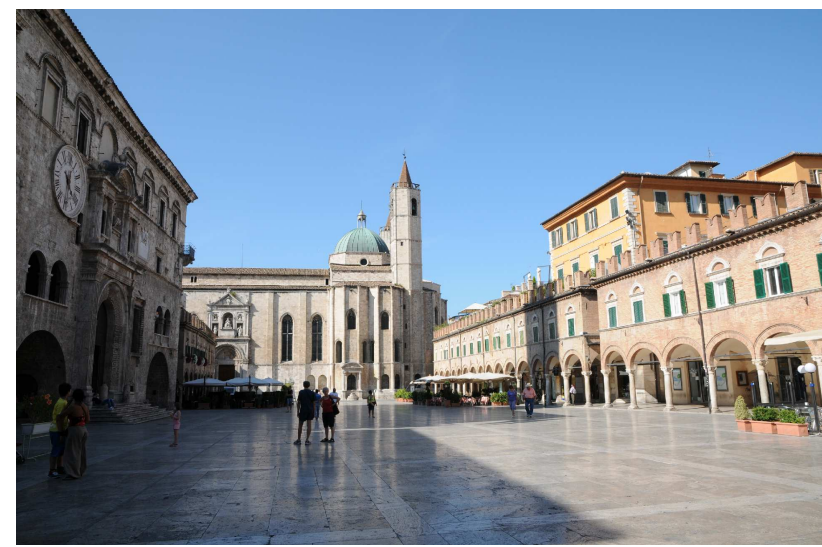

Figure 2. Piazza del Popolo

\section{EXPERIMENTATION: CONSTRUCTION OF A DIGITAL ATLAS THROUGH A GIS}

\subsection{The 2D map}

The experiment on the construction of the $2 \mathrm{D}$ map was conducted using free and open source software, and specifically GRASS and QuantumGIS ("user-friendly" interface for GRASS).

With the Geographic Information System GRASS (Geographic Resources Analysis Support System), edit and distributed under the terms of the GNU (General Public License), it's possible to manage, develop, model and visualize geographic data two and three-dimensional. It is considered a standard in the segment for its strong data processing capabilities, but it is characterized by a not very friendly interface which tends to limit its spread. For this reason it was decided to also use the software QGIS (QuantumGIS). QGIS is integrated with GRASS and presents a user interface similar to the equivalent commercial GIS packages, it has also some easy functions and interesting plugin. Spatial data processed in GRASS can be vector or raster. In the first case they are denoted by the coordinates and the type of geometry (points, lines, surfaces); in the second case they are organized by a regular grid (matrix cells), where each cell (pixel) is assigned an alphanumeric value representing the attribute.

In particular in GRASS a vector model is the set of geometry, topology, attributes and its relationships.

The geometric objects are characterized by the topological structure (which governs the spatial relationships between different elements, like the connection, the adjacency or the inclusion) and can be traced to five types: the point (represented by a pair of coordinates), the line (stored by a sequence of coordinate pairs the nodes - the ends' points - and summits - the intermediate points), the boundary (to represent the edge of closed areas, which is stored by a sequence of coordinate pairs of nodes and vertices), the centroid (element point represented by a pair of coordinates) and the area (a closed boundary with a centroid).

Each topological-geometric object is then described by attributes organized in a database. The management of vector data in GRASS is accomplished primarily through a spatial database extension (*.dbf), but integrated with external relational database that, if properly selected, allows greater speed and safety during the update, the search and the access for contemporary multiple users.

\subsection{Courtyards and cloisters: information architecture}

The main objective of the experience was to test a possible procedure aimed at increasing the effectiveness of traditional GIS information through the creation of 3D interfaces, focusing on exploration based on perception criteria. Accordingly, the description of the individual architectural elements was carried out only in the alternative to the main objective, and was considered more than adequate at this stage of research, focusing exclusively on the main features.

The first step in documenting the closed areas consisted in the census and location on the map.

During the design of the areas on the map, the system assigns to each geometry a sequence number (unique identification code), to which it was decided to assign an additional alphanumeric code chosen for the research purposes, consisting of 3 letters and 3 numbers (cor00n for courtyards, cloisters for chs00n).

The surveyed property, composed by 35 cloisters and courtyards, is first described through its architectural style, name, location and a free-text field (for notes and an indication of the location of a possible secondary access).

For a description of planimetric areas there are: the name of the plant type, the description of the 4 fronts/sides (as distinct from a number, where 1 is the side facing north, 2 east, 3 and 4 south and west), the type of access to space, any additional qualification of access, the presence of the scale and its position.

The type system provides an answer to closed vocabulary: 4 sides, 3 sides, 2 continuous sides, two not continuous sides, 1 side. The description of the 4 sides provides only an indication, the presence or the absence of a porch or a tamponed. The type of access is described by choosing a response from those indicated by the closed vocabulary that are directed by road, entrance hall, hallway passing, more. In the further qualification of access (the compilation is not required) more importance is given to the intrados of the roof which is generally vaulted. For the staircase must be shown the presence (yes or no) and the position related to the closed space, or, in other words, if it adherent, external or other.

Such information has helped to identify for each cloister or court, the number of floors/levels, the number of sides open galleries on each level, the placement of access and its type, the presence and disposition of the body scale toward the general space.

The second group of information is intended to illustrate the morphology plant in elevation. The fields provided for each of the four sides describe: the number of levels (indicated by number), the architectural order at various levels, the further qualification of the order, the lower surface of the fabric. These fields are repeated for each side.

For a description of the architectural order in high, the answers must be selected from a closed vocabulary (column, pillar, infill wall, etc.) and listed in sequence from bottom to top, separated by a comma. Further characterization is made in the next field (open dictionary) through the description of the base and the capital, if they are present. Even for the intrados of the roof, the answers must be selected from a closed vocabulary (barrel vault, groin vault, barrel vault with lunettes, flat roof, truss, rafters, etc.) and listed in sequence from the bottom up and separated by commas.

The three types of information are the themes showed of the information system and each one has the icons for all categories of attributes, so to communicate immediately their information on the map. 


\begin{tabular}{|c|c|c|c|c|c|c|c|c|c|c|c|c|c|c|c|}
\hline & CAT & MYID & CODICE_C & TIPOLOGIA & DENOMINAZI & UBICAZIONE & NOTE & LIVELLO1 & VELLC & VELLLC & VELLL $~=$ & TIPO_ACCES & QUAL_ACC & SCALA & POS_SCA \\
\hline 0 & 1 & & cor001 & cortile & cortile pala... & via dei Bon... & accesso se... & 3 lati & 3 lati & 3 lati & I & androne pa... & androne vo... & si & normale \\
\hline 1 & 2 & 1 & cor002 & cortile & cortile pala... & corso Mazz... & & 3 lati & I & I & & androne & androne vo... & si & normale \\
\hline 2 & 3 & & chs006 & chiostro & chiostro ch... & piazza San ... & accesso se... & 3 lati & 3 lati & I & I & altro & corridoio s... & si & altro \\
\hline 3 & 4 & 3 & chs008 & chiostro & chiostro po... & corso Mazz... & & 4 lati & I & & & altro & androne vo... & si & normale \\
\hline 4 & 5 & 4 & cor007 & cortile & cortile pala... & piazza del ... & & 2 lati continui & 1 lato & 3 lati & & altro & ingresso & si & in aderenz \\
\hline 5 & 6 & & cor009 & cortile & cortile pala... & via Mercan... & & 2 lati continui & I & I & 1 lato & androne ta... & androne vo... & si & in aderenz \\
\hline 6 & 7 & & cor010 & cortile & cortile pala... & corso Mazz... & accesso se... & 2 lati continui & 1 lato & 1 lato & & androne pa... & androne vo.... & si & normale \\
\hline 7 & 10 & 9 & chs 012 & chiostro & chiostro di ... & corso Vitto... & accesso se... & 4 lati & I & & & androne ta... & androne vo... & si & normale \\
\hline 8 & 11 & 10 & cor013 & cortile & cortile pala... & via Pretori... & accesso se... & 3 lati & 3 lati & & & androne pa... & androne vo.... & si & normale \\
\hline 9 & 12 & 11 & chs 014 & chiostro & chiostro pi... & via Dino An... & accesso se... & 4 lati & 4 lati & & & altro & & no & esterno \\
\hline 10 & 14 & 14 & cor016 & cortile & cortile pala... & corso diso... & & 4 lati & I & I & & altro & & si & normale \\
\hline 11 & 15 & 15 & chs 017 & chiostro & chiostro mi... & via Antonio... & accesso se... & 4 lati & 4 lati & & & androne & soffitto piano & si & normale \\
\hline 12 & 16 & 16 & chs018 & chiostro & chiostro m... & via d' Ancar... & & 4 lati & I & & & androne ta... & soffitto piano & ? & ? \\
\hline 13 & 17 & 17 & cor019 & cortile & cortile pala... & corso Mazz... & & 3 lati & 3 lati & 3 lati & & androne & androne vo... & si & normale \\
\hline 14 & 18 & 18 & cor020 & cortile & cortile dell'... & largo Giard... & & 4 lati & I & & & altro & corridoio & ? & ? \\
\hline 15 & 19 & 19 & cor021 & cortile & cortile pala... & via Bonapa... & & 1 lato & 1 lato & 1 lato & & androne & androne vo... & si & normale \\
\hline 16 & 20 & 20 & chs022 & chiostro & chiostro pa... & corso Vitto... & accesso se... & 2 lati continui & I & I & & androne ta... & androne vo.... & si & normale \\
\hline 17 & 24 & 24 & coro27 & cortile & cortile in vi... & via dei Con... & & 3 lati & & & & androne ta... & androne vo... & si & normale \\
\hline 18 & 26 & 26 & cor030 & cortile & cortile pala... & corso Mazz... & & 2 lati continui & 1 lato & 1 lato & & androne ta... & androne vo... & si & in aderenz \\
\hline 19 & 27 & 27 & cor035 & cortile & cortile pala... & corso Mazz... & & 2 lati continui & 1 lato & I & & androne & androne vo... & si & normale \\
\hline 20 & 28 & 28 & cor031 & cortile & cortile pala... & via lannella, 5 & accesso se... & 2 lati continui & 2 la... & I & I & androne ta... & androne vo... & si & normale \\
\hline 21 & 30 & 30 & chs033 & chiostro & chiostro di... & via s. Angel... & & 4 lati & I & & & altro & vestibolo & si & esterno \\
\hline 22 & 31 & 31 & cor034 & cortile & cortile pala... & via del Trivi... & & 2 lati continui & 2 la... & 2 la... & & androne & androne vo... & si & normale \\
\hline 23 & 32 & 32 & chs004 & chiostro & chiostro mi... & viale della ... & accesso se... & 4 lati & 1 lato & I & & altro & diretto da ... & si & normale \\
\hline 24 & 33 & 33 & chs005 & chiostro & chiostro m... & viale della ... & accesso se... & 4 lati & 4 lati & & & altro & loggiato vo... & si & in aderenz \\
\hline
\end{tabular}

Figure 3. Table of attribute of the layer courtyards

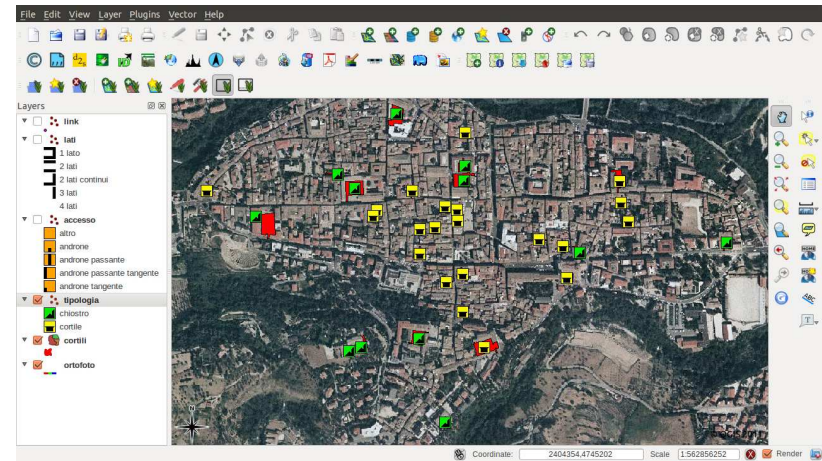

Figure 4. Courtyards and cloisters on the map

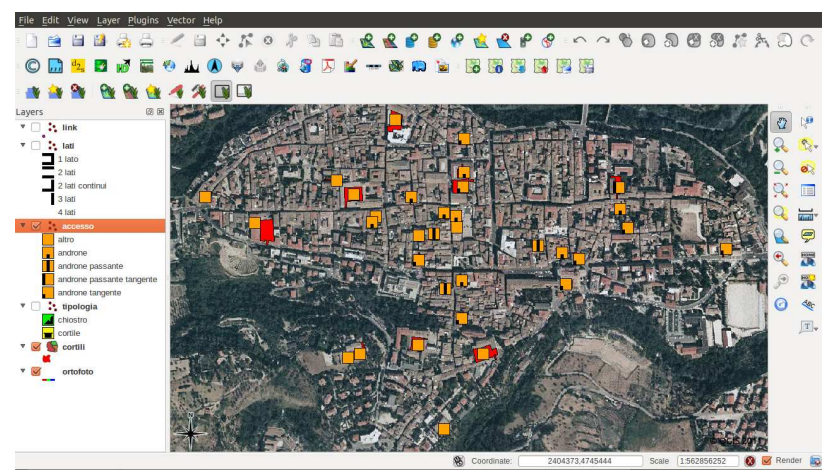

Figure 5. Icons to identify the type of access

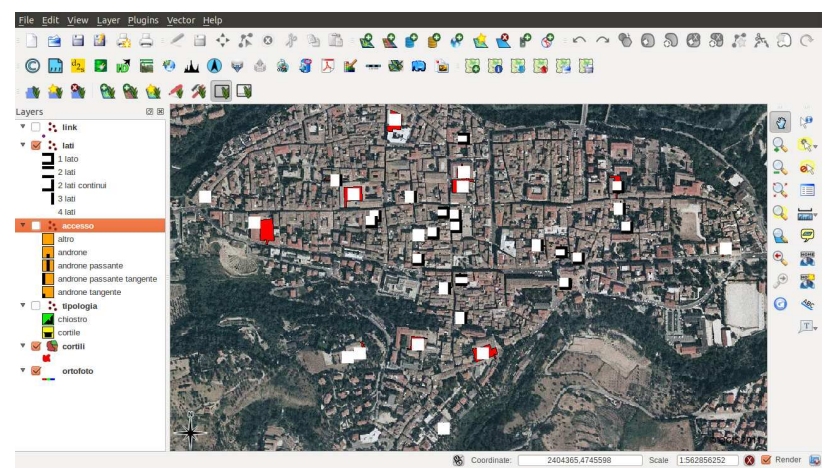

Figure 6. Icons to identify numbers and type of sides

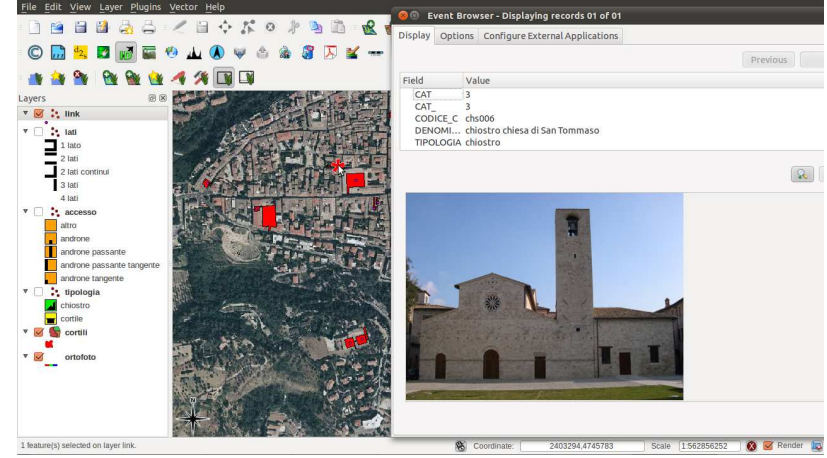

Figure 7. Links to photographic resources

\section{THE CONSTRUCTION OF THE 3D SISTEMS}

\subsection{The construction of 3D models: Photo Modeling}

The digital atlas, composed by textual or graphical documents, photos or technical drawings, finds its main focus on the digital three-dimensional models of the courtyards and cloisters of the urban space in Ascoli Piceno. As far as the measurement and the representation are concerned, such models can be considered as an extreme qualified synthesis of the knowledge of one architectural work, made by the expression of their form and their material quality. These have been built and had textures applied through a direct method, via image-based modeling procedure, which is a proper way to get to know a large number of historical architectural buildings, without using long methods such as geometrical surveys.

Besides, the image-based modeling process introduces new approaches such as the chance of dealing with one operative technique that includes phases which are separated and different from each other, giving us the opportunity of having the overall plastic intelligence of the object studied.

This is possible through some digital automatic calculations, using a simple and economic tool such as the photograph as a tool to register reality. Because of its capacity of building fast and efficient measurable 3D models out of a real buildings, starting from images of different moments of their life, we can assume that it is a easily scalable method, mainly used for 

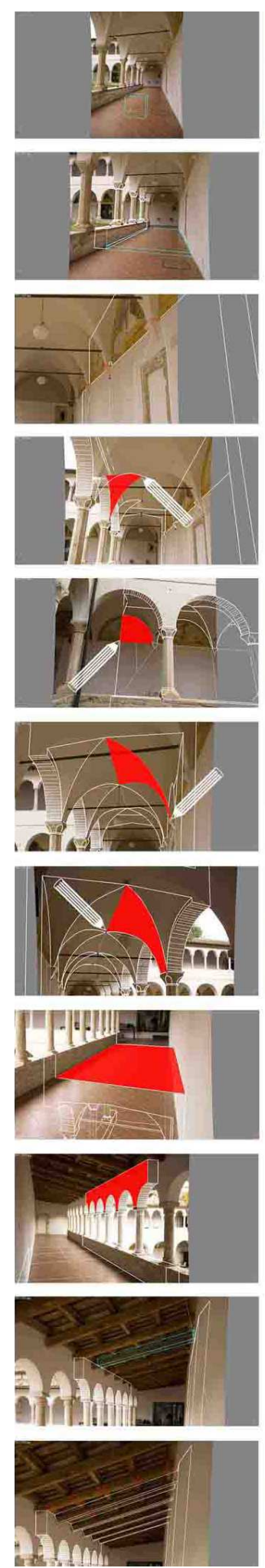

Figure 8. Cloister of Annunziata: poligonal modeling
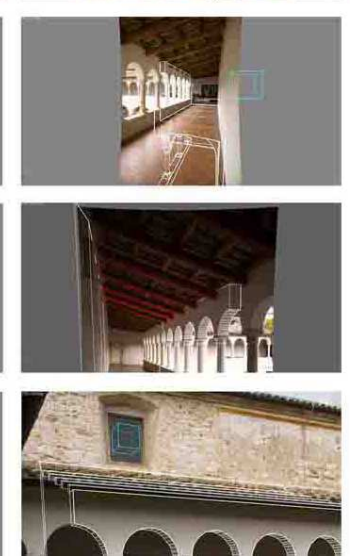
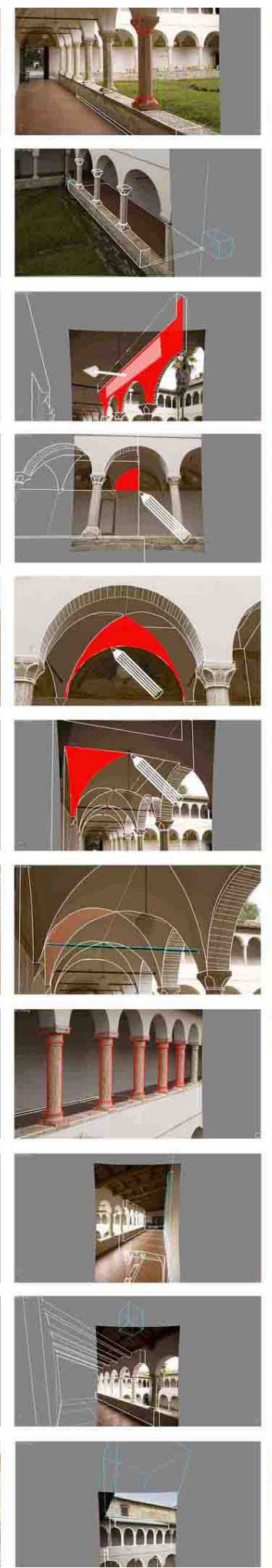
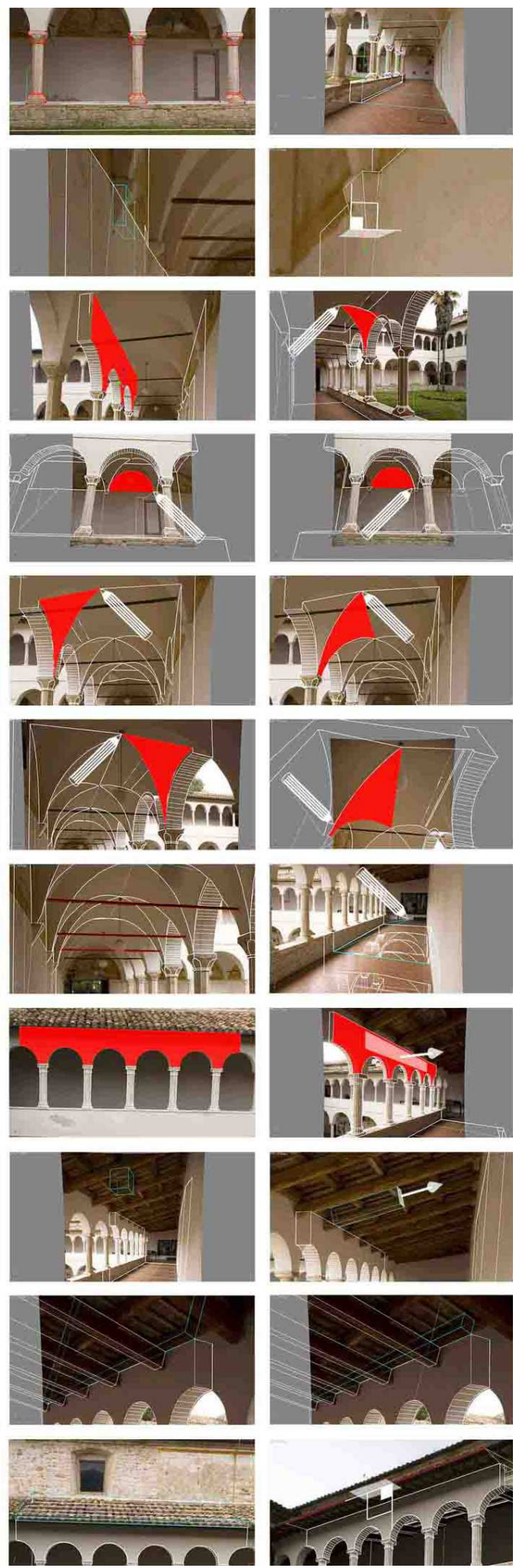

project that may need accurate geometrical surveys. Such process consists of four different logical moment of whom only the first one ends on the site: the shooting campaign of the building/object; the orientation of every single photogram; the elaboration of a three-dimensional model; the texturing phase of it with measurements and textures of the real coating material.
The construction of such a model represent a moment of criticism and comprehension of the spatial intelligence of the architectonic text; a meditation that has to be taken as a chance to have an interpretation of the different parts and their relations but also to find and classify the stylistic details of components. A moment of meditation that is necessary especially if related to 
operative methods which have to be as good as possible for a better virtual representation.

We also had to deal with a particular case study. Infact these closed spaces are hybrid spaces belonging to the indoor and the outdoor spaces at the same time. These kind of spaces are geometrically well defined: walls, floors, truss together with more complex elements such all kinds of vaults. Such architectonic primitives need a shooting campaign with images which are divergent from the centre of the space we want to represent. On the contrary, we needs convergent photo to describe columns.

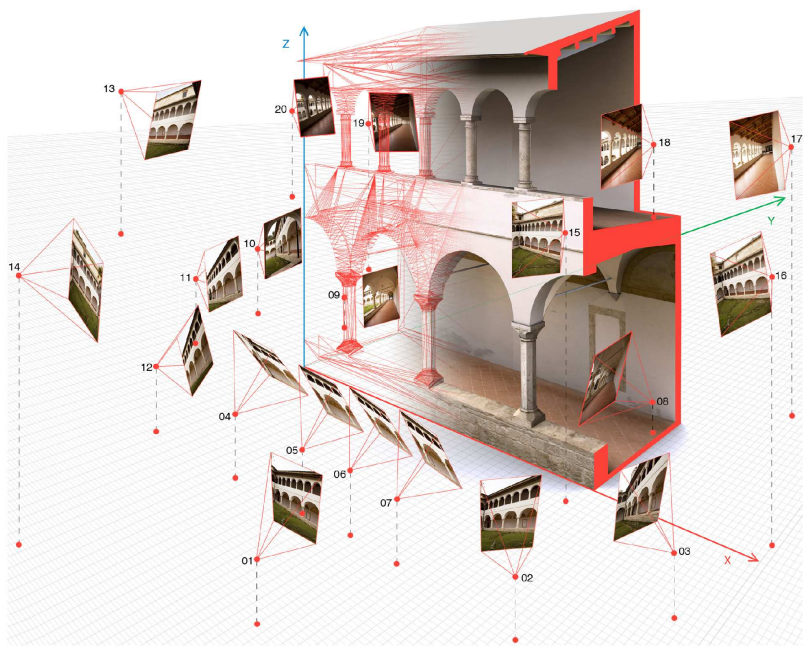

Figure 9. Cloister of Annunziata: orientation of the cameras

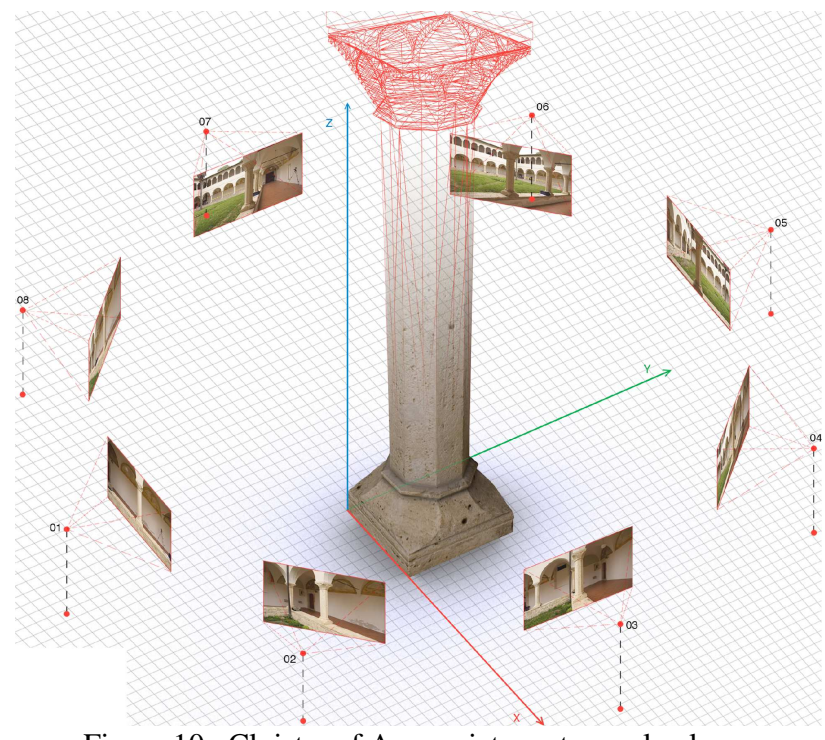

Figure 10. Cloister of Annunziata: octagonal column

We encountered many difficulties for the orders on first or second floor, because of overhangs or fences often prevented us from leaning towards them.

All these methods, allowed by the availability of modeling tools included in the software Autodesk ImageModeler2009 we use, belong to a repertory of the so-called polygonal modeling. That allows us to describe only the shell of the object being analyzed, while not letting us know more about mass or density. Moreover it does need to generate closed and congruent volumes, it does not use Boolean operators to define free form surfaces and because of this flexible qualities finds in the photo modeling based on photographic images its own application field.

The use of such procedures has finally made it possible to obtain excellent results for the comprehension and representation of the good quality architecture in historical contexts, thanks to the amount of information (understanding of the architectural geometry), to the amount of information (textures) and to precision in measurements also with tools with average technological capacities (low cost cameras). The realization of digital models together with realistic textures, adding photometric information to the morphology of the object, have become extremely useful to read not only the geometrical form but also the material qualities, superficial textures, the surfaces degradation and so on.

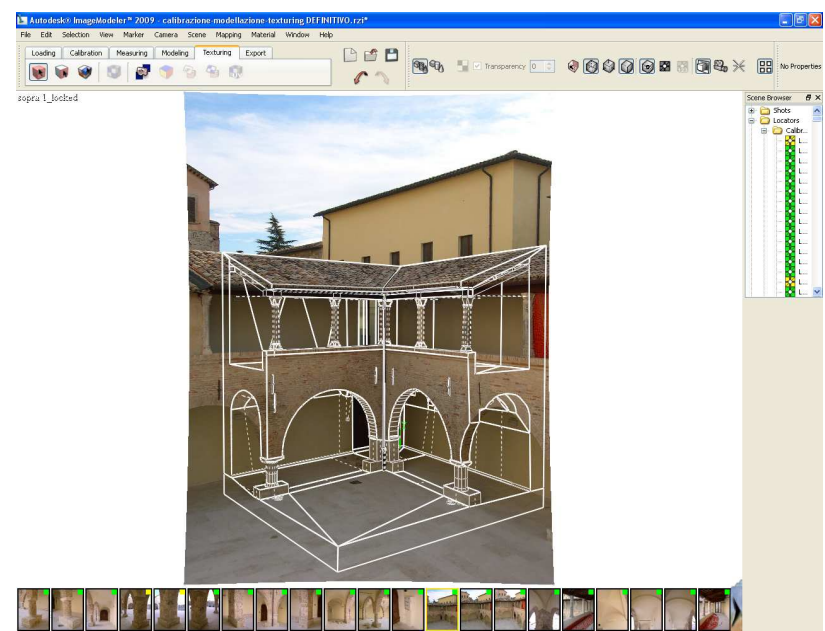

Figure 11. Cloister of San Tommaso church: wireframe model

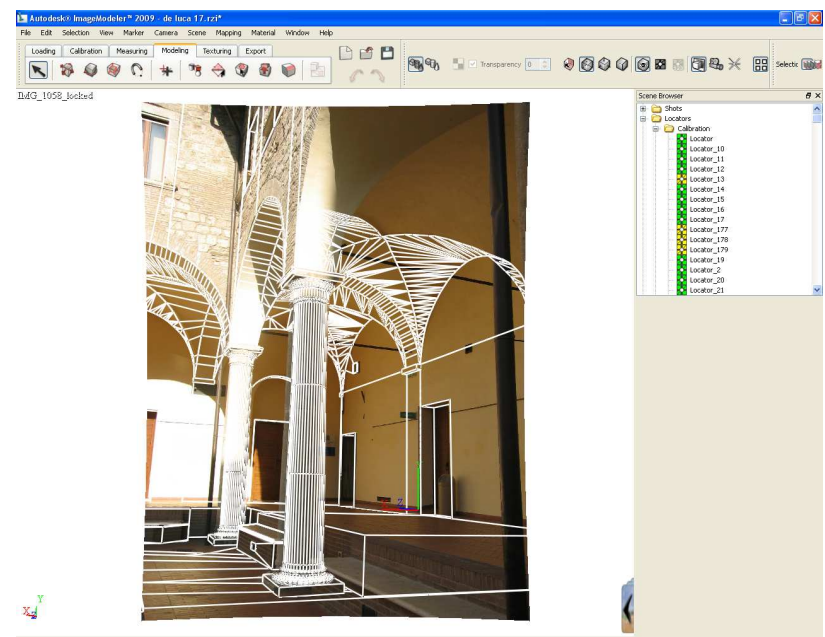

Figure 12. Cloister of Sant'Agostino: wireframe model

\subsection{The 3D map}

Currently, the term 3D-GIS refers to two main types of products: digital elevation model (DEM and DTM) and graphical environment of the latest generation of satellite navigation systems that uses 3D models of buildings, neighbourhoods or entire cities, to make the environment more similar to the reality.

In both cases the information got through these 3D models are few: a digital elevation model is a raster file, so it's possible to query it only about the coordinates of each pixel; these 
information can be obtained in a 3D browser, but cannot be managed and processed from a database.

One of the objectives of the experimentation is to verify the possibility of increasing the representation of free and open source GIS using the 3D-GIS models like interfaces to access at the information. Usually the main GIS software allows the 3D creation through the extrusion of polygons. Also GRASS, the software we used, can build a volume through the command v.extrude, it creates a $3 \mathrm{D}$ vertical line from a point, a line $3 \mathrm{D}$ from a line 2D, a face (a 3D area) from a boundary (the border line to describe an area) and a volume (faces and kernel) from an area (the topological composition of centroid and boundary); (a centroid is a point within a closed boundary and a kernel is a $3 \mathrm{D}$ centroid in a volume).

When we started our work it was not possible to correspond a database or an attribute table to a 3D geometry, actually, a 3D model was not a real vector model (vector model defined in GRASS as the set of geometry, topology, attributes and their relationships).

Develop the 3D model of courtyards and cloisters directly in GRASS is impossible, so it was decided to import different georeferenced three-dimensional models, made using other softwares (section 3.1), visible in 2D through the Map Display 1 window and in 3D through the GRASS module NVIZ.

This method was considered satisfactory about the objective of increasing the sense of representation in a GIS environment, but not about the goal to create a 3D model like interface to access at the information; in fact these models were not connected to the external database, and therefore it was not possible to make any queries.

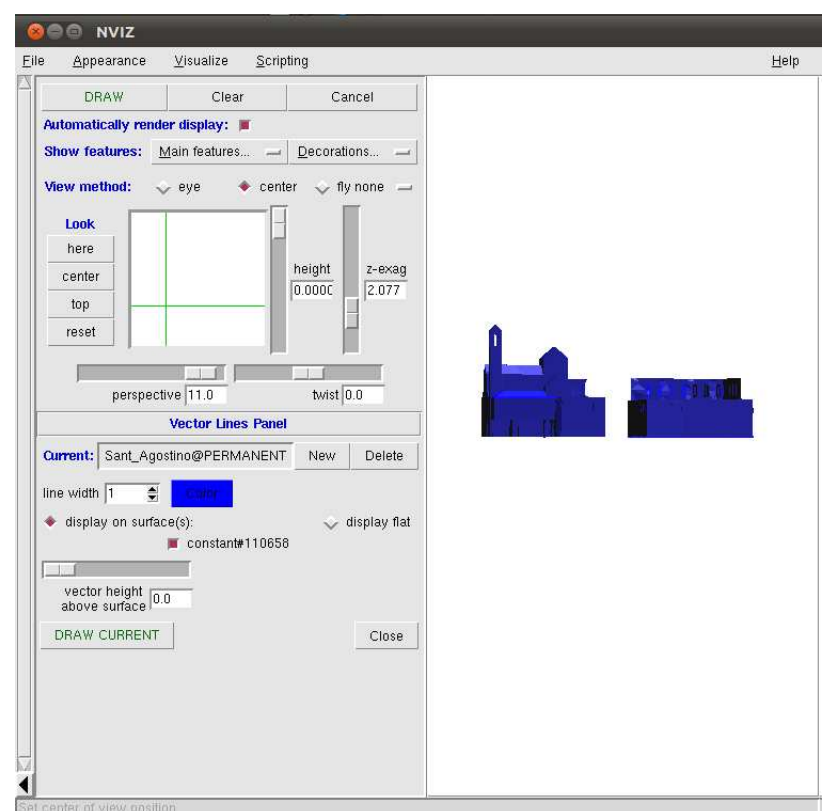

Figure 13. S. Tommaso and St. Agostino: 3D models in NVIZ

For this reason we tried with other techniques: we made queries to the $3 \mathrm{D}$ models through the $3 \mathrm{D}$ points.

Therefore the idea was to "hide" under each 3D model a threedimensional vector point (characterized by geometry, topology and attributes explicitly in a file .dbf) which makes the connection to the database containing information about our courtyards and cloisters. In this way NVIZ is exploited beyond its typical features, which are essentially 3D display, through the only useful option: Vector Query Panel.
From these points is then possible to derive graphic themes, assigning colour, shape and size varying according to the assume values that the attributes in the database are connected. If through the model it was not possible to formulate queries, through the related $3 \mathrm{D}$ point was possible to access at all the information entered into the database.

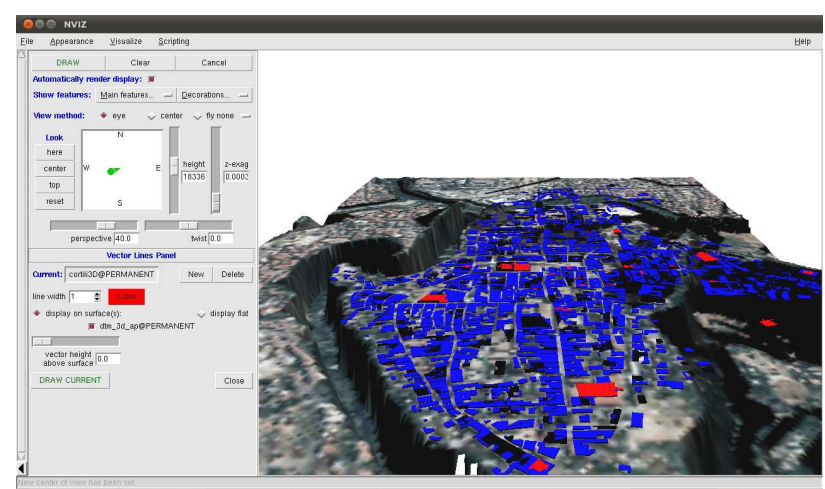

Figure 14. DTM with building (blue) and cloisters (red)

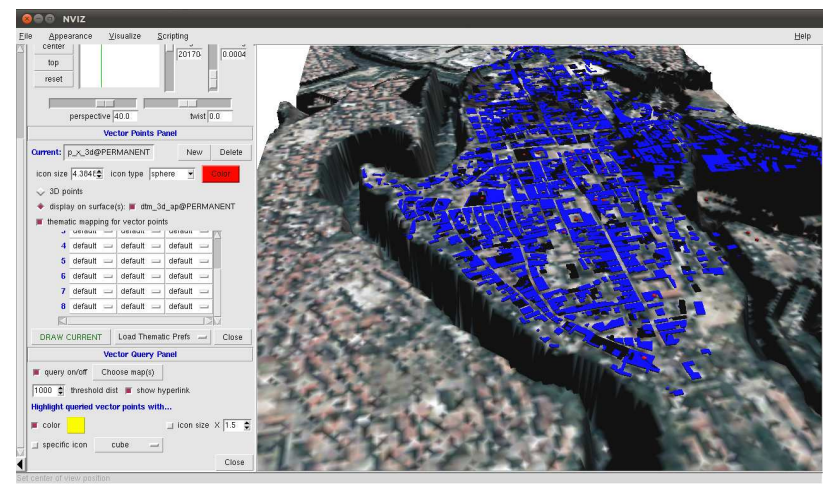

Figure 15. DTM with building and vector points (red)

Today the software is able to create a table of attributes for each uploaded 3D model; in a table of attributes there are written the information about the geometry of the object.

This innovation allows to query the $3 \mathrm{D}$ model in the browser without the use of expedient because through its ID the 3D model can be connected to a database, even if there are some limits about the implementation of the attribute table and about a good visualization through the browser NVIZ.

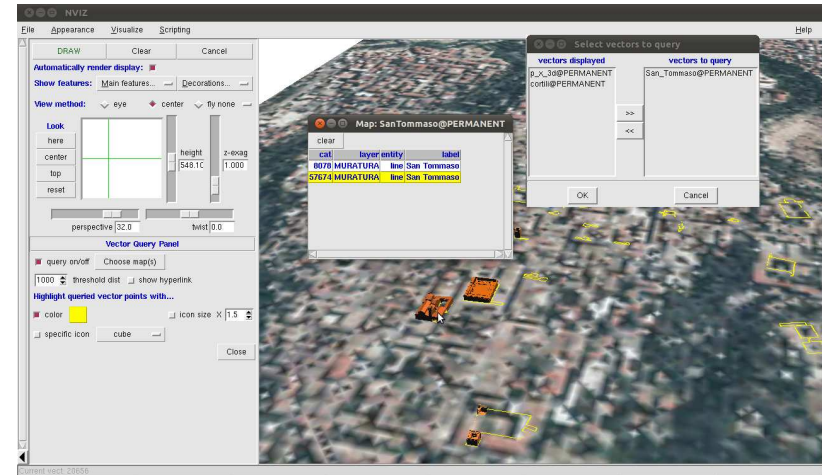

Figure 16. Query at the 3D models in NVIZ 


\section{CONCLUSIONS}

The objective of the experiment was to achieve a geographic information system oriented at the architecture of the closed areas of cloisters and courtyards of Ascoli Piceno. At the center of the analysis there was the architectural object, its individual qualities and its relations with the context, the urban space, so the attention was directed not only to the object itself, but also to its relationship with other similar and/or contemporary.

The experiment was carried out with the intention of identifying a possible procedure to allow large-scale applications without significant investment of financial commitment and therefore it was a "realistic" experience and an effective action for protection, management and promotion of cultural heritage.

About the technical developments, in the end it was possible to interrogate the $2 \mathrm{D}$ objects from the map, but also through threedimensional space, where the 3D object becomes a syntactic and semantic organizer of information.

The next goal is to improve the procedures for viewing through the $3 \mathrm{D}$ browser and create a similar system accessible from the web.

\section{References}

Buttussi, F., Chittaro, L., Coppo, M., 2007. Using Web3D Technologies for Visualization and Search of Signs in an International Sign Language Dictionary, Proceedings of Web3D. In: 12th International Conference on $3 D \mathrm{Web}$ Technology, ACM Press, New York, pp. 61-70.

Centofanti, M., Mingucci, M., 2008. DISEGNARECON n. 2/2008. Digital Magazine, Dipartimento di Architettura e Pianificazione territoriale, Università di Bologna.

De Luca, L., 2011. La fotomodellazione architettonica. Rilievo, modellazione, rappresentazione di edifici a partire da fotografie. Editore Flaccovio Dario, Palermo.

El-Hakim, S., Remondino, F., Voltolini, F., 2008. Integrating Techniques for Detail and Photo-Realistic 3D Modelling of Castles. In: GIM International, Vol.22(3), pp. 21-25.

Ippoliti, E., 2010. Mappe, modelli e tecnologie innovative per conoscere, valorizzare e condividere il patrimonio urbano. Indagini sperimentali di sistemi integrati sul Piceno. In: Sistemi informativi integrati per la tutela la conservazione e la valorizzazione del patrimonio architettonico e urbano. Gangemi, Roma, pp. 240-251.

Ippoliti, E., Moscati, A., 2010. Interfacce di accesso alle informazioni: tra 3D, 3D-GIS e Web Gis. In: Sistemi informativi [...]. Gangemi, Roma, pp. 310-319.

Ippoliti E., Moscati, A., 2010. New means of knowledge: 3D, 3D-GIS and Web GIS. In: XIII International Congress of Architectural Graphic Expression, Actas, Valencia 27-29 de majo 2010, Universitat Politecnica de Valencia. Editorial de la Universitat Politecnica de Valencia, Valencia.

Meschini, A., 2010. La progettazione del modello dei dati: tra standard e caso studio. In: Sistemi informativi integrati [...]. Gangemi, Roma, pp. 271-283.
Moscati, A., 2010. Architettura delle informazioni: il database. In: Sistemi informativi integrati [...]. Gangemi, Roma, pp. 284291.

Moscati, A., 2010. Architettura delle informazioni e dati geografici 2D: database e GIS. In: Sistemi informativi integrati [...]. Gangemi, Roma, pp. 302-309.

Neteler, M., Mitasova, H., 2008. Open Source GIS: A GRASS GIS Approach. Third Edition, Springer, New York.

Rossi, D., 2010. Rappresentare le informazioni: interpretare, visualizzare, pubblicare dati geografici. In: Sistemi informativi integrati [...]. Gangemi, Roma, pp. 252-259.

\section{References from websites}

GRASS GIS (Geographic Resources Analysis Support System): http://grass.ibiblio.org/grass63/manuals/html63_user/vectorintro .html (accessed january 2011).

\section{Acknowledgements}

Part of present work was developed during the studio workshop in Digital Drawing in the first year of graduate level in Architetcure of the School of Architecture and Design in Ascoli Piceno, University of Camerino. So a special thanks goes to all the students of the lab. The authors also would like to thank Livio de Luca and Francesco Cervellini for their support, Luca Foresi and Mariateresa Cusanno for their work. 